\title{
PEMODELAN PENENTUAN PRIORITAS RENAKSI (RENCANA AKSI REHABILITASI \& REKONSTRUKSI) MENGGUNAKAN METODE ARAS
}

\author{
Lenny Margaretta Huizen 1 , Agusta Praba Ristadi Pinem 2
}

\author{
1,2, Program Studi Teknik Informatika, Fakultas Teknologi Informasi dan Komunikasi Universitas Semarang, \\ 1 lenny@usm.ac.id,_2agusta.pinem@usm.ac.id
}

\begin{abstract}
Abstrak
Seiring dengan berkembangnya teknologi sekarang ini, kecepatan sebuah informasi diperlukan untuk pengambilan keputusan, karena sebuah Informasi yang diterima akan menjadi pedoman didalam seseorang atau organisasi mengambil langkah selanjutnya. Informasi merupakan sekumpulan data yang telah diproses sehingga menjadi sesuatu yang lebih bermanfaat. Kelengkapan data dan informasi yang berkualitas akan mempunyai pengaruh terhadap pengambilan keputusan. Penentuan prioritas sangat diperlukan pada RENAKSI (Rencana AKsi Rekonstruksi dan Rehabilitasi) agar dapat diketahui mana yang akan mendapatkan penanganan terlebih dahulu. Metode ARAS (Additive Ratio Assessment) merupakan satu dari beberapa metode pengambilan keputusan yang penggunaannya melalui perangkingan yang menjadi dasar penilaian dengan berpegang teguh bahwa sebuah pilihan yang sudah dipilih mempunyai kedekatan dengan data sebenarnya. Hasil yang diperoleh bahwa pemodelan untuk menentukan prioritas pada RENAKSI dengan menggunakan Metode ARAS didpatkan nilai sebesar sebesar 0,9636 dan hasil dari penelitian ini tidak jauh berbeda dari data set history yang digunakan sebagai pembanding. Metode sistem pengambil Keputusan yang mempunyai fungsi nilai yang optimum dapat menghasilkan nilai korelasi dasar yang lebih baik.
\end{abstract}

\section{Keywords: ARAS, Sistem Pengambilan keputusan}

\section{Pendahuluan}

Sekarang ini, kecepatan sebuah informasi diperlukan untuk pengambilan keputusan seiring dengan berkembangnya teknologi, karena sebuah Informasi yang diterima akan menjadi pedoman didalam seseorang atau organisasi mengambil langkah selanjutnya. Informasi merupakan sekumpulan data yang telah diproses sehingga menjadi sesuatu yang lebih bermanfaat. (Turban,dkk,2008). Kelengkapan data dan informasi yang berkualitas akan mempunyai pengaruh terhadap pengambilan keputusan. Ada beberapa model yang digunakan dalam pengambilan keputusan dalam menentukan penentuan skala prioritas yang dapat diselesaikan dengan Multicriteria Decision Making (MCDM). MCDM merupakan sebuah teknik dimana pengambilan suatu keputusan untuk beberapa pilihan yang ada. MCDM dapat digunakan untuk berbagai kasus pengambilan keputusan seperti mendiaknosa penyakit dengan berbasis web (Nur,H,2012), memberikan rekomendasi seorang dokter untuk melakukan kunjungan sehat kepada pasien (David S, dkk,2019), selain itu MCDM dapat digunakan untuk membantu dalam pemilihan Kantor Urusan Agama (KUA) teladan (Heru F, dkk,2015).
Metode ARAS merupakan salah satu metode yang ada pada MCDM. Metode yang dikembangkan Edmundas Kazimieras Zavadkas dan Zenonas Turskis pada tahun 2010 (Edmundas dan Zenonas,2010). ARAS (Additive Ratio Assessment) merupakan satu dari beberapa metode pengambilan keputusan yang penggunaannya melalui perangkingan yang menjadi dasar penilaian dengan berpegang teguh bahwa sebuah pilihan yang sudah dipilih mempunyai kedekatan dengan data sebenarnya (Kersuliene dan Turkis, 2014). Beberapa studi kasus menyebutkan bahwa metode ARAS dapat digunakan sebagai pemilihan team leader terbaik pada sebuha perusahaan (Luman G, dkk.2018), rekomendasi pasien kunjungan sehat (David S, dkk,2019), Pada penelitian yang lain metode ini digunakan untuk menentukan penerima kredit pada sebuah koperasi (Charis M, dkk,2019). Dari beberapa contoh kasus yang berbeda pada penggunaan metode ARAS, ada keterkaitan cara penggunaan metode ARAS ini yaitu dengan melihat beberapa kriteria yang sudah ditentukan sejak awal. Pada penelitian ini, peneliti mengambil dari sebuah studi kasus pada RENAKSI (Rencana Aksi Rehabilitasi dan Rekonstruksi) pada wilayah yang terdampak bencana alam. Bisa kita lihat di Indonesia 
merupakan sebuah negara yang sangat rawan bencana alam karena di Inodesia dikelilingi oleh lempeng tektonik aktif, beberapa gunung berapai serta leaknya yang dilewati oleh garis khatulistiwa (BNPB, 2019). Salah satunya gempa bumi. RENAKSI sendiri merupakan sebuah dokumen yang berisi hasil dari catatan rancangan yang sebagaimana dimaksudkan sebagai hasil penyusunan rencana rehabilitasi dan rekonstruksi yang akan dilakukan dalam periode waktu tertentu (BNPB, 2010), sebagai bahan pertimbangan pada RENAKSI di Indonesia penggunaan dataset pada ECLAT (Economic Commission for Latin Carribbean)dilakukan. Pembagian ini dibagi menjadi beberapa hal yaitu dari segi kemanusiaan serta fisik. Dalam hal ini yaitu memberikan sebuah penilaian mengenai kerugian serta kerusakan dari sebuah bencana alam serta hal-hal yang dibutuhkan oleh manusia sebagai awal pemulihan. Dari keduanya ini kemudian menghasilkan sebuah data yaitu kebutuhan mana yang dibutuhkan setelah bencana alam. Dari data tersebut digunakan sebagai nilai kriteria serta pilihan pada matrix keputusan.

Metode ARAS selanjutnya dilakukan uji coba untuk dapat menghasilkan tujuan utama dengan melakukan urutan pilihan dari beberapa kriteria yang sudah ditentukan.

\section{Metode Penelitian}

Kelengkapan data serta informasi yang baik mempunyai pengaruh yang besar terhadap keputusan yang akan dilakukan, sehingga penentuan prioritas pada RENAKSI diperlukan.

\subsection{Sistem Pendukung Keputusan (SPK)}

Sistem pendukung keputusan merupakan sebuah metode yang dapat digunakan oleh seseorang dengan kondisi serta situasi yang kurang terstruktur (Turban, dkk,2005). Untuk menghasilkan sebuah informasi berupa tingkatan pilihan yang optimal, Metode SPK memerlukan sebuah perhitungan matematis (Mardani, dkk, 2015). SPK sendiri dapat digunakan untuk mengambil sebuah keputusan lebih dari satu ahli (Kutut,dkk, 2014). SPK digunakan bukan untuk mengotomatisasi sebuah keputusan akan tetapi hanya untuk memberikan sebuah pilihan (Kusrini, 2007).

\subsection{Metode ARAS (Additive Ratio \\ Assessment) \\ ARAS menggunakan perangkingan untuk} memperoleh bobot dengan membandingkan nilai untuk kriteria pada masing-masing pilihan (Charis M, dkk, 2019).
Penelitian ini menggunakan metode ARAS digunakan sebagai perankingan karena memiliki prinsip intuitif serta rasioal yang tidak kecil untuk menghasilkan sesuatu yang optimal. Fungsi dari utilitas ini menentukan ketepatan melalui sebuah perangkingan untuk membandingkan nilai dari setiap kriteria masing-masing.

Menurut nalar bahwa sebuah kriteria akan ditimbang serta dinormalkan yang dapat menggambarkan pilihan yang maksimal. Pada metode MCDM yaitu dengan membandingkan sebuah nilai utilitas yaitu dengan nilai solusi alternative positif serta negative akan menjadi hal yang dipertingkankan (Kocak dkk, 2018).

Ada beberapa langkah yang dilakukan untuk perhitungan dengan menggunakan Metode ARAS, yaitu:

1. Membentu Decision Making Matriks

$$
x=\left[\begin{array}{ccccc}
x_{01} & \cdots & x_{0 j} & \cdots & x_{0 n} \\
\vdots & \ddots & \vdots & \ddots & \vdots \\
x_{i j} & \cdots & x_{i j} & \cdots & x_{n j} \\
\vdots & \ddots & \vdots & \ddots & \vdots \\
x_{n 1} & \cdots & x_{m j} & \cdots & x_{m n}
\end{array}\right] i=m, 0 ; j=1, n(1)
$$

$\mathrm{m}$ merupakan jumlah alternative, $\mathrm{n}$ adalah jumlah kriteria, xij merupakan nilai kriteria dari pilihan I sedangkan xoj merupakan nilai optimum dari sebuah kriteria $\mathrm{j}$.

2. Normalisasi pada Decision Making Matriks pada kriteria yang sudah ada.

$$
X_{i j}^{*}=X_{i j} / \sqrt{\left[\sum_{i=1}^{m} X_{i j}^{2}\right]}
$$

3. Matrik keputusan yang ternormalisasi pada semua kriteria

$$
\begin{gathered}
\bar{x}=\left[\begin{array}{ccccc}
\bar{x}_{01} & \cdots & \bar{x}_{0 j} & \cdots & \bar{x}_{0 n} \\
\vdots & \ddots & \vdots & \ddots & \vdots \\
\bar{x}_{i j} & \cdots & \bar{x}_{i j} & \cdots & \bar{x}_{n j} \\
\vdots & \ddots & \vdots & \ddots & \vdots \\
\bar{x}_{n 1} & \cdots & \bar{x}_{m j} & \cdots & \bar{x}_{m n}
\end{array}\right] i=\bar{m}, 0 ; j=1, \bar{n} \\
i=\bar{m}, 0 ; j=1, \bar{n}
\end{gathered}
$$

4. Menentukan bobot pada matriks yang sudah ternormalisasi

$$
\sum_{j=1}^{n} w_{j}=1
$$

5. Menentukan nilai dari fungsi optimum 


$$
s_{i} \sum_{j=1}^{n} \hat{x}_{i j} ; \quad i=\overline{0, m}
$$

6. Menentukan tingkatan peringkat

$$
K_{i} \frac{S_{i}}{S_{0}} ; \quad i=\overline{0, m}
$$

Jika nilai alternative pilihan menghasilkan alternative yang terbaik.dengan nilai ' $\mathrm{K}$ ' maka dapat menghasilkan rangking. Gambar 1 berikut ini merupakan gambaran mengenai alur penelitian

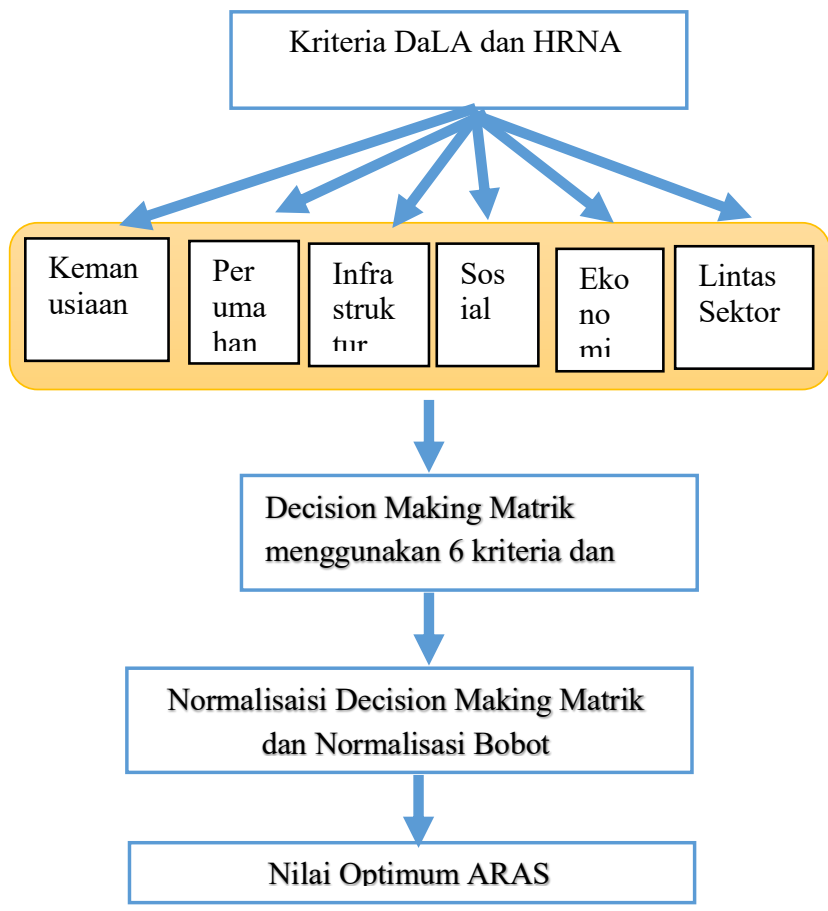

\section{Gambar 1 Bagan Tahapan Penelitian}

\subsection{RENAKSI (Rencana Aksi Rehabilitasi dan Rekonstruksi )}

Indonesia merupakan salah satu negara yang ssangat rentan dengan bencana alam, gempa bumi. Hal ini disebabkan karena sebuah kondisi dimana Indonesia terletak diantara 3 lempeng tektonik yaitu Lempeng Indo-Australia-lempeng Eurasi serta Lempeng Pasifik. (BNPB,2019).

Pada penanggulangan bencana alam proses RENAKSI diperlukan, selain itu terdapat komponen mengacu pada aspek fisik serta kemanusiaan yaitu Damages and Losses Assessment (DaLA) atau Penilaian Kerusakan dan Kerugian serta Human Recovery Need Assesment (HRNA) atau Pengkajian Kebutuhan Pemulihan Manusia (Kurniawan dkk, 2011).
Aspek kemanusiaan, Perumahan, Insfrastruktur, Ekonomi, Sosial serta Lintas Sektor merupakan aspek utama untuk proses rehabilitasu dan rekonstruksi (BPNP,2011). Nominal kerusakan dijadikan inputan untuk system serta dilakukan perangkingan. Pada Tabel 1 merupakan tabel perkiraan yang diakibatkan oleh bencana alam.

\section{Tabel.1 Perkiraan Nilai Kerusakan

\begin{tabular}{|c|c|c|c|}
\hline $\begin{array}{c}\text { Lingku } \\
\text { ngan }\end{array}$ & $\begin{array}{c}\text { Bagian } \\
\text { Lingkung } \\
\text { an } \\
\end{array}$ & Satuan & Nilai Kerusakan \\
\hline \multirow{2}{*}{$\begin{array}{c}\text { Kemanu } \\
\text { siaan }\end{array}$} & Korban & Jiwa & - \\
\hline & Populasi & Jiwa & - \\
\hline $\begin{array}{c}\text { Peruma } \\
\text { han }\end{array}$ & $\begin{array}{c}\text { Perumaha } \\
\mathrm{n}\end{array}$ & Unit & $\begin{array}{c}\text { Jumlah rumah } \\
\text { yang terdampak } \times \\
\text { Harga satuan } \\
\end{array}$ \\
\hline \multirow{4}{*}{$\begin{array}{l}\text { Infrastr } \\
\text { uktur }\end{array}$} & Jalan & Unit & $\begin{array}{c}\text { Jalan rusak per } \\
\mathrm{km} \times \text { Harga } \\
\text { satuan }\end{array}$ \\
\hline & Sungai & Unit & $\begin{array}{l}\text { Sungai rusak per } \\
\mathrm{m} \times \text { Harga satuan }\end{array}$ \\
\hline & Energi & Unit & $\begin{array}{c}\text { Kerusakan unit } \times \\
\text { Harga satuan }\end{array}$ \\
\hline & $\begin{array}{l}\text { Air dan } \\
\text { Sanitasi }\end{array}$ & Unit & $\begin{array}{c}\text { Kerusakan } \\
\text { infrastruktur } \\
\text { PDAM × Harga } \\
\text { satuan } \\
\end{array}$ \\
\hline \multirow[t]{3}{*}{ Sosial } & Kesehatan & Unit & $\begin{array}{c}\text { Kerusakan } \\
\text { bangunan } \\
\text { kesehatan } \times \text { Harga } \\
\text { satuan } \\
\text { Kerusakan } \\
\text { bangunan tempat } \\
\text { ibadah } \times \text { Harga } \\
\text { satuan } \\
\end{array}$ \\
\hline & $\begin{array}{l}\text { Tempat } \\
\text { Ibadah }\end{array}$ & Unit & $\begin{array}{c}\text { Kerusakan } \\
\text { bangunan } \times \text { Harga } \\
\text { satuan }\end{array}$ \\
\hline & $\begin{array}{l}\text { Panti } \\
\text { Sosial }\end{array}$ & Unit & $\begin{array}{c}\text { Kerusakan lahan } \\
\text { pertanian } \times \text { Harga } \\
\text { satuan hektar }\end{array}$ \\
\hline \multirow{3}{*}{$\begin{array}{l}\text { Ekonom } \\
\text { i }\end{array}$} & Pertanian & ha & $\begin{array}{c}\text { Jumlah rumah } \\
\text { rusak } \times \text { Harga } \\
\text { satuan } \\
\end{array}$ \\
\hline & Perikanan & Unit & $\begin{array}{c}\text { Jumlah rumah } \\
\text { rusak } \times \text { Harga } \\
\text { satuan } \\
\end{array}$ \\
\hline & UKM & Unit & $\begin{array}{c}\text { Jumlah rumah } \\
\text { rusak } \times \text { Harga } \\
\text { satuan } \\
\end{array}$ \\
\hline $\begin{array}{l}\text { Lintas } \\
\text { Sektor }\end{array}$ & $\begin{array}{c}\text { Pemerinta } \\
\mathrm{h}\end{array}$ & Unit & $\begin{array}{c}\text { Jumlah rumah } \\
\text { rusak } \times \text { Harga } \\
\text { satuan } \\
\end{array}$ \\
\hline
\end{tabular} (BNPB, 2011).}


Pengembangan Rekayasa dan Teknologi, Vol 16, No.1, Juni 2020, pp 82-87

p-ISSN: $1410-9840$ \& e-ISSN: $2580-8850$

http://journals.usm.ac.id/index.php/jprt/index

\begin{tabular}{|c|c|c|c|}
\hline $\begin{array}{c}\text { Lingku } \\
\text { ngan }\end{array}$ & $\begin{array}{c}\text { Bagian } \\
\text { Lingkung } \\
\text { an }\end{array}$ & Satuan & Nilai Kerusakan \\
\hline & Keamanan & Unit & $\begin{array}{c}\text { Jumlah rumah } \\
\text { rusak } \times \text { Harga } \\
\text { satuan }\end{array}$ \\
\cline { 2 - 4 } & & Unit & $\begin{array}{c}\text { Jumlah rumah } \\
\text { rusak } \times \text { Harga } \\
\text { satuan }\end{array}$ \\
\hline
\end{tabular}

\section{Hasil dan Pembahasan}

Penelitian ini menggunakan data sekunder yaitu data yang didapat dari BAPPENAS. Langkah yang pertama adalah membentuk decision making matrix yaitu dengan 6 kriteria untuk setiap alternative berdasar sub kriteria serta kriteria.

Pada tahap kedua yaitu normalisasi decision making matrix menggunakan Persamaan 2 langkah ini digunakan untuk memperoleh nilai kriteria 0 sampai 1 dan nilai bobot juga dilakukan normalisasi sehingga jumlah keseluruhan nilai bobot adalah 1 .

Pada metode ARAS penambahan alternatof 0 digunakan sebagai salah satu pilihan yang dapat mempengaruhi normalisasi.

Tabel 2 Normalisasi Matrik keputusan

\begin{tabular}{|l|r|r|r|r|r|r|}
\hline Alt & \multicolumn{1}{|l|}{1} & \multicolumn{1}{l|}{ C2 } & \multicolumn{1}{l|}{ C3 } & \multicolumn{1}{l|}{ C4 } & \multicolumn{1}{l|}{ C5 } & \multicolumn{1}{l|}{6} \\
\hline A0 & 0.488 & 0.630 & 0.606 & 0.612 & 0.663 & 0.670 \\
& 1 & 1 & 9 & 2 & 9 & 6 \\
\hline A1 & 0.488 & 0.630 & 0.517 & 0.073 & 0.320 & 0.670 \\
& 1 & 1 & 5 & 3 & 8 & 6 \\
\hline A2 & 0.019 & 0.004 & 0.001 & 0.000 & 0.000 & 0.003 \\
& 5 & 6 & 8 & 0 & 0 & 1 \\
\hline A3 & 0.052 & 0.006 & 0.003 & 0.000 & 0.000 & 0.006 \\
& 7 & 2 & 3 & 0 & 0 & 2 \\
\hline A4 & 0.023 & 0.005 & 0.010 & 0.000 & 0.000 & 0.000 \\
& 2 & 9 & 2 & 0 & 0 & 0 \\
\hline A5 & 0.006 & 0.000 & 0.000 & 0.000 & 0.000 & 0.061 \\
& 6 & 3 & 2 & 0 & 0 & 6 \\
\hline A6 & 0.005 & 0.002 & 0.001 & 0.000 & 0.000 & 0.000 \\
& 9 & 3 & 4 & 0 & 0 & 0 \\
\hline A7 & 0.354 & 0.389 & 0.521 & 0.392 & 0.663 & 0.025 \\
& 2 & 4 & 5 & 6 & 9 & 5 \\
\hline A8 & 0.187 & 0.161 & 0.072 & 0.160 & 0.082 & 0.004 \\
& 2 & 0 & 4 & 7 & 0 & 8 \\
\hline A9 & 0.050 & 0.038 & 0.065 & 0.154 & 0.065 & 0.306 \\
& 7 & 2 & 6 & 7 & 4 & 3 \\
\hline A1 & 0.097 & 0.065 & 0.126 & 0.029 & 0.048 & 0.004 \\
0 & 8 & 2 & 6 & 8 & 5 & 4 \\
\hline A1 & 0.092 & 0.150 & 0.073 & 0.143 & 0.047 & 0.046 \\
1 & 0 & 2 & 8 & 1 & 0 & 2 \\
\hline
\end{tabular}

Setelah mencari nilai matrik keputusan selanjutnya adalah mencari nilai optimum berdasarkan baseline dengan Alternatif 0 karena Alternatif 0 sudah menjadi salah satu yang masuk ke metode, sehingga hasil yang diperoleh dapat dilihat pada Tabel 3.
Tabel 3 Nilai Optimum

\begin{tabular}{|c|l|c|r|}
\hline Alternatif & Kabupaten & $\sum \mathrm{ij}$ & $\mathrm{Ki}$ \\
\hline A1 & Klaten & 0.6051 & \\
\hline A2 & Magelang & 0.4657 & 0.769560507 \\
\hline A3 & Boyolali & 0.0057 & 0.009463777 \\
\hline A4 & Sukoharjo & 0.0136 & 0.022481497 \\
\hline A5 & Wonogiri & 0.0078 & 0.012831884 \\
\hline A6 & Purworejo & 0.0092 & 0.01515103 \\
\hline A7 & Bantul & 0.0020 & 0.003230878 \\
\hline A8 & Sleman & 0.4047 & 0.668850907 \\
\hline A9 & Yogyakarta & 0.1190 & 0.196589582 \\
\hline A10 & Kulonprogo & 0.0980 & 0.161875444 \\
\hline A11 & Gunung Kidul & 0.0674 & 0.111381849 \\
\hline
\end{tabular}

Pada tabel 5 Nilai yang diperoleh pada masing-masing alternatif dibagi dengan nilai optimum dari alternatif 0 kemudian hasil yang diperoleh dibandingkan dengan data asli yaitu mencari nilai korelasi.

Alternatif 0 mempunyai peran yaitu pada proses normalisasi hingga penentuan nilai fungsi optimum. Hasil diperoleh dari perhitungan Metode ARAS dapat dilihat pada Tabel 4.

\section{Tabel 4. Hasil Implementasi metode ARAS}

\begin{tabular}{|l|l|l|l|l|}
\hline Kabupaten & Alt & $\begin{array}{l}\text { Total } \\
\text { Alternatif }\end{array}$ & Rank & History \\
\hline Klaten & A1 & 0.770 & 1 & 1 \\
\hline Magelang & A2 & 0.009 & 5 & 5 \\
\hline Boyolali & A3 & 0.022 & 2 & 2 \\
\hline Sukoharjo & A4 & 0.013 & 4 & 4 \\
\hline Wonogiri & A5 & 0.015 & 3 & 3 \\
\hline Purworejo & A6 & 0.003 & 6 & 6 \\
\hline Bantul & A7 & 0.669 & 1 & 1 \\
\hline Sleman & A8 & 0.197 & 2 & 2 \\
\hline Yogyakarta & A9 & 0.162 & 3 & 5 \\
\hline Kulonprogo & A10 & 0.111 & 5 & 3 \\
\hline $\begin{array}{l}\text { Gunung } \\
\text { Kidul }\end{array}$ & A11 & 0.156 & 4 & 4 \\
\hline
\end{tabular}


Dari Tabel.4 hasil perangkingan metode ARAS dengan dengan data history hanya terdapat sedikit perbedaan, hasil korelasi dengan rank spearman dapat digunakan sebagai alat ukur tingkat korelasi ranking dengan berdasar data histori, dan hasil yang didapat adalah sebesar 0,9636 .

Pada penelitian ini penggunaan metode korelasi dasar juga dilakukan sebagai pembanding uji validasi dan hasil yang diperoleh adalah 0,849 . Gambar 2 dibawah ini merupakan Grafik validasi histori untuk perbandingan data histori dan Metode ARAS.

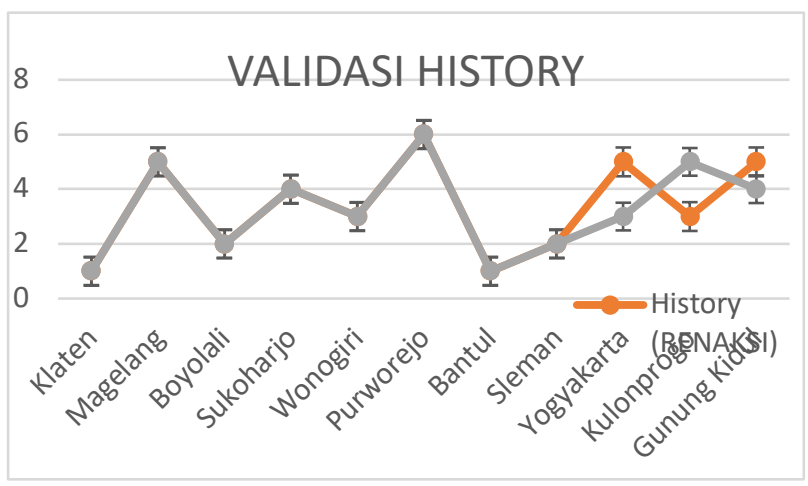

\section{Gambar 2. Validasi Histori}

Dari gambar diatas dapat dilihat bahwa perbandincan antara data histori dan hasil perhitungan dengan metode ARAS mempunyai hasil yang tidak terlalu jauh dengan data histori.

\section{Kesimpulan}

Setelah penelitian dilakukan, hasil diperoleh bahwa hasil dari metode ARAS dapat digunakan sebagai penentu prioritas daerah yang terdampak bencana. Hal ini dapat dilihat bahwa hasil dari korelasi dengan rank spearman sebesar 0,9636 dan hasil dari penelitian ini tidak jauh berbeda dari data set history yang digunakan sebagai pembanding. Metode sistem pengambil Keputusan yang mempunyai fungsi nilai yang optimum dapat menghasilkan nilai korelasi dasar yang lebih baik.

\section{Daftar Pustaka}

Abbas, M., Ahmad. J., Edmundas. K. Z. (2015). Fuzzy Multiple Criteria Decision Making Techniques and Application-Two Decades review from 1994 to 2014. Expert System with Application, Vol 42, Hal. 4126-4148.

BNPB, 2010. Perka BNPH Pedoman Umum Penyelenggaraan Rehabilitasi dan
Rekonstruksi Pasca Bencana. Badan Nasional Penanggulangan Bencana, Jakarta. BNPB, 2010. Perka BNPH Pedoman Umum Penyelenggaraan Rehabilitasi dan Rekonstruksi Pasca Bencana. Badan Nasional Penanggulangan Bencana, Jakarta.

Charis, M., Aria, H., dan Agusta. P. R. P. (2019)., Pemodelan Penentuan Kredit Simpan Pinjam Menggunakan Metode Additive Ratio Assessment (ARAS). Pengembangan Rekayasa dan Teknologi, Vol 15, No. 1, hal. 7-11.

David, S., Dwi, M. M, Rahmi, H.(2019). Implementasi Metode Addive Ratio Assesment (ARAS) Untuk Rekomendasi Pasien Kunjungan Sehat Pada Fasilitas Kesehatan Tingkat Pertama Dr. Josepb Nugroho H. S. Jurnal Komputer dan Aplikasi, Vol 07, No. 03, Hal 109-119.

Kusrini.(2007). Sistem Pendukung Keputusan dan Aplikasinya, Yogyakarta.

Kutut, V., Zavadskas, E.K., Lazauskas, M. (2014). Assessment of priority alternatives for preservation of historic buildings using model based on ARAS and AHP methods. Arch. Civ. Mech. Eng. 14, 287-294.

Kocak, S., Kazaz, A., Ulubeyli, S.(2018). Subcontractor selection with additive ratio assessment method. J. Constr. Eng. Manag. Innov. Vol. 1, Hal. 18-32.

Lumban, G.L.C dan Hassibuan, N. A. (2018). Sistem Pendukung Keputusan Pemilihan Team Leader Shift TerbaikDengan Menggunakan Metode ARAS Studi Kasus PT. Anugrah Busana Indah. Majalah INTI, 16-21.

Heru, F., Desi, A., Aan, E.(2015). Implementasi Metode MCDM Dalam Pemilihan kantor Urusan Agama(KUA) Teladan Dengan Menggunakan Promethee(Studi Kasus: Kementerian Agama Kepahiang). Jurnal Rekursif, Vol. 3, No. 2, Hal 196-207.

Kersuliene, V., Turskis, Z.(2014). An Integrated Multi-criteria Group Decision Making Process: Selection of the Chief Accountant. Procedia - Soc. Behav. Sci. 110, 897-904

Nur, H. C.(2012). Sistem Pendukung Keputusan Dengan Metoda multi-Criteria Decision Making (MCDM). Jurnal Informatika dan Teknologi Informasi, Vo. 8, No.2, Hal.103108

Turban, E. (2005). Decision Support System and Intelligent System Edisi Bahasa Indonesia Jilid I, Andi, Yogyakarta. 
Pengembangan Rekayasa dan Teknologi, Vol 16, No.1, Juni 2020, pp 82-87

p-ISSN: 1410-9840 \& e-ISSN: 2580-8850

http://journals.usm.ac.id/index.php/jprt/index

Turban, Leidner, McLean, dan Wetherbe.2008. Information Technology for management, $6^{\text {th }}$ ed:John Wiley \& Sons (Asis)Pte Ltd.

Zavadskas, E.K., Turskis, Z.(2010). A new additive ratio assessment (ARAS) method in multicriteria decision-making. Technol. Econ. Dev. Econ. Vol. 16, Hal. 159-172. 